\title{
A step toward the definition of ecological indicators of the impact of fishing on the fish assemblage of the Abore reef reserve (New Caledonia)
}

\author{
Marion Amand ${ }^{1,2}$, Dominique Pelletier ${ }^{2, a}$, Jocelyne Ferraris ${ }^{3}$ and Michel Kulbicki ${ }^{1}$ \\ 1 IRD Centre de Nouméa, Unité de Recherche CoRéUs, 110 promenade Roger Laroque, BP A5, 98848 Nouméa Cedex, Nouvelle-Calédonie \\ 2 IFREMER Centre de Nantes, Laboratoire de Mathématiques appliquées à l'Exploitation des Ressources halieutiques et aquacoles \\ (MAERHA), 2 rue de l'île d'Yeu, BP 21105, 44311 Nantes Cedex 03, France \\ 3 IRD-UR CoRéUs / EPHE, Université de Perpignan, 52 avenue Paul Alduy, 66860 Perpignan Cedex, France
}

Received 4 November 2003; Accepted 8 June 2004

\begin{abstract}
Marine Protected Areas (MPA) are often contemplated as a tool for the sustainable management of exploited resources and ecosystem conservation. This paper proposes an approach to establish a statistical diagnostic of the effects of MPAs on fish assemblages, and define corresponding ecological indicators. This requires choosing relevant variables (abundance, diversity, demographic parameters...) and appropriate statistical methods. The study was based on data from the Abore reef Reserve in New Caledonia. Two sets of methods: 1-inferential linear models (ANOVA, GLM); 2- Partial Least Squares (PLS) methods of regression, were used to test the effects of this MPA. PLS enabled us to test simultaneously within a model, density, species richness, biomass and mean size variables of fish community to retain the most sensitive and relevant ones. Habitat variability was also taken into account in these models. Species were grouped according to several criteria: 1- feeding habit; 2- taxonomy; 3- mobility; 4- adult size; 5- demographic strategy. No significant effect of the opening of the Abore reef to fishing was found for mobility. Feeding habit was the only criterion for which the results from the inferential models and PLS showed a significant effect of reserve status for all variables. Species richness, density, and to a lesser extent mean size, were sensitive to the removal of reserve status, but not biomass. Results from ANOVA and PLS regression were consistent but the latter allows a more holistic approach as it integrates all variables within a single model.
\end{abstract}

Key words: Marine protected areas / Fish / Coral reef / Fishing impact / Ecological indicators / PLS regression / New Caledonia

\begin{abstract}
Résumé - Vers la définition d'indicateurs écologiques de l'impact de la pêche sur l'assemblage spécifique des poissons de la réserve Aboré (Nouvelle-Calédonie). Les Aires Marines Protégées (AMP) sont de plus en plus considérées comme des mesures de gestion alternative permettant à la fois une gestion durable des ressources exploitées et la conservation des écosystèmes. Nous proposons une approche pour définir des indicateurs synthétiques et permettre un diagnostic statistique de l'effet des AMP sur les peuplements. Ce travail passe par le choix de variables pertinentes (abondance, richesse spécifique, paramètres démographiques, etc.) et de méthodes statistiques appropriées. Cette étude a été réalisée sur la réserve du récif Aboré en Nouvelle-Calédonie. Les données issues de deux campagnes scientifiques menées sur ce récif sont utilisées pour tester globalement l'effet des AMP grâce à des modèles linéaires inférentiels (ANOVA, GLM), et par des méthodes de régression PLS (Partial Least Squares). Ces dernières permettent de confronter dans un même modèle quatre variables (densité, richesse, biomasse et taille moyenne des poissons), afin de retenir les plus sensibles et les plus pertinentes pour l'évaluation de l'impact de la réserve. La variabilité de l'habitat est également prise en compte dans la modélisation. Les espèces sont regroupées selon plusieurs critères : 1- le régime alimentaire; 2- la taxonomie ; 3- la mobilité ; 4- des caractéristiques démographiques ; 5- des caractéristiques de taille. Les espèces, quel que soit leur mobilité, n'apparaissent pas affectées par l'ouverture à la pêche du récif Aboré, qu'elles soient sédentaires ou très mobiles. Seul le critère trophique révèle un effet du changement de statut Réserve/Non Réserve pour toutes les variables, à la fois d'après les modèles inférentiels et les régressions PLS. Les résultats des modèles inférentiels et des régressions PLS montrent que la richesse spécifique et la densité sont les variables les plus sensibles à l'impact de l'ouverture à la pêche. La taille moyenne est également bien modélisée sur l'ensemble des résultats mais pas la biomasse. Les résultats d'ANOVA et de régression PLS sont cohérents mais la régression PLS permet d'intégrer toutes les variables dans un même modèle.
\end{abstract}

a Corresponding author: dpellet@ifremer .fr 


\section{Introduction}

Coral reef ecosystems are characterised by a large fauna and flora diversity. These ecosystems are complex and fragile and they are threatened by anthropogenic (e.g. demographic development, urbanisation and tourism) and natural perturbations. In New Caledonia, industrial activities in particular open pit mining and agricultural activities, the development of tourism and the increase of urbanisation have negative impacts on the reef systems (Labrosse et al. 2000). A substantial economic activity is supported by the lagoon resources, either directly (fishing), or indirectly (selling of fishing gear, fuel, boats, etc.) (Boncoeur 2002). Lagoon resources also have a major cultural and recreative importance for the three main local ethnic groups (Melanesian, European and Polynesian) (Leblic 1999). Fishing practices are diverse due to cultural, ethnic or socio-economic factors. Most lagoon fishing is done from small boats or from the shore, and subsistence and recreative fishing catch more fish than commercial exploitation.

Such coastal ecosystems and fish communities must be protected from anthropogenic influences. Marine Protected Areas (MPAs) are a conservation tool aimed at protecting, even temporarily, part of the ecosystem from human influence with the purpose of restoring both fish communities and habitat. MPAs have good records as management and protection measures that conserve and allow regeneration of ecosystems reefs (Agardy 1994, 2000; Sumaila et al. 2000; Wantiez et al. 1997).

Establishment of MPAs results in effects inside the reserve and induced effects outside the reserve (Bohnsack 1990; Roberts and Polunin 1991; Zeller et al. 2003). The assessment of these effects has motivated a large number of studies. Most of them consider only a restricted number of species and evaluate effects per species. Sometimes, species are grouped on the basis of taxonomic criteria (e.g. Alcala 1988; Jennings et al. 1996; Letourneur 1996; Wantiez et al. 1997) or feeding habits (Russ and Alcala 1996; Chiappone et al. 2000). We are not aware of studies considering the whole fish assemblage. Most studies evaluate the effect of MPAs on density, biomass or mean size and show positive results for these variables inside the reserve compared to outside. For species richness results may not be generalized as they vary from case to case. Reserve effects which are most striking for commercial species (Bohnsack 1990; Bohnsack et al. 1994; Chiappone et al. 2000; Francour 1994; Russ and Alcala 1998) are sometimes mitigated due to other factors that may influence the structure of fish assemblages, like habitat or interspecific relationships (Polunin and Roberts 1993; Grigg 1994). Thus, accounting for habitat is particularly relevant to analyse and understand the spatio-temporal variations of fish communities (Sale 1998).

The evaluation of the MPA's impact in the perspective of monitoring fish communities may be linked with the search of ecological indicators. We here define an indicator as a function of observations, which value indicates the present status and/or dynamics of the system of interest (FAO 1999). Indicators may be used to establish diagnostics and evaluate risks related to changes in the system. For instance, the index of biotic integrity of Karr (1981) quantifies the level of perturbation of a fish community. In recent years, indicators have become an important issue in environmental sciences, e.g. in fisheries science (Garcia et al. 2000). Defining indicators of
MPA efficiency requires finding the most relevant biological variables to depict reserve effect.

In the present paper, a statistical approach is proposed to define indicators for monitoring the fish community of the Abore reef reserve (New Caledonia). This reserve had been in place for 3 years, when part of it was opened to fishing for two years, then closed again. Our approach considers the whole community and accounts for habitat. We wish to determine which of the variables density, biomass, mean size and species richness are the most relevant to evaluate the impact of this opening to fishing, i.e. the most sensitive to this impact. To account for the whole fish assemblage, these variables were estimated for several species groups, based on several criteria linked to life history traits and behaviour. Two different statistical models were used for evaluating this impact, linear models (ANOVA and GLM) and PLS regression. They allowed us to test the effect of the removal of reserve status on the fish community, and to suggest appropriate ecological indicators.

\section{Marine reserves in New Caledonia}

The New Caledonia archipelago is located in the SouthWestern Pacific at the tip of the Melanesian Arc. The total area of the mainland and surrounding islands amounts to $19100 \mathrm{~km}^{2}$ and corresponding coral reefs surface is $8000 \mathrm{~km}^{2}$ (Dandonneau et al. 1981). The New Caledonia barrier reef is the second largest in the world (after the Great Barrier Reef) with a length of $1600 \mathrm{~km}$. Located near the IndoPacific Center of Biodiversity, the terrestrial and coastal marine biodiversities are very high compared to other islands in the South Pacific. The coral reef ecosystem can be divided into three major reef types that show significant differences in their fish assemblages (Kulbicki 1997): coastal fringing reefs, intermediate reefs in the lagoon, and the barrier reef separating the lagoon from the ocean. Abore reef $\left(148 \mathrm{~km}^{2}\right)$ is part of this barrier reef. It is $25 \mathrm{~km}$ long and $18 \mathrm{~km}$ off Noumea, the largest city with more than 100000 inhabitants.

In New Caledonia, there are 3 kinds of fisheries: offshore, coastal and lagoon fisheries. Marine reserves concern only the lagoon fishery. This fishery targets mainly the following families: Acanthuridae, Scaridae, Lethrinidae, Lutjanidae and Serranidae. The major gears are spear gun, handlines, trolling and gillnets. Catch is mostly for subsistence and to a lesser extent for sale on local markets (Virly 2001). In New Caledonia marine reserves have been established to preserve coral reef habitats, their resources, and their uses (fishing, recreative activities and tourism) (Sarramegna 2000). Presently, all 16 existing MPAs of New Caledonia are located in the South Province. The Department of Natural Resources relies on scientific assessment to justify the closure of particular zones by local authorities. For this purpose, they are interested in ecological indicators to monitor habitats and resources. The University of New Caledonia has been monitoring all the MPAs in the South West lagoon since 1990 with surveys every 4 years on a number of selected sites within and next to these MPAs. The present paper focusses on the Abore reef reserve. Its status changed over years. From 1990 to 1993, it was one among three areas included in a system of rotational closures on the barrier reef. Every three years, two of the three reserves 
within the system were opened to fishing, while the third one (which happened to be Abore during these years) was closed. This system was abandoned in August 1993. At that date, two thirds of Abore reef were opened to fishing, the remaining third kept as an MPA. A survey was implemented to follow the fishing pressure and its impact (Sarramegna 2000). The biomass accumulated over the three year closure was fished within a few weeks because of a strong fishing pressure. This revolving system was abandoned and it was decided to close the entire Abore reef to fishing in August 1995. Pelletier et al. (2004) assessed the impact of the opening to fishing on fish density. In the present paper, we were rather interested at an overall assessment involving several variables, in the view of defining indicators of fishing impact.

\section{Materials and methods}

\subsection{Data}

To monitor the impact of the change in reserve status due to the partial opening to fishing of Abore reef, a survey was conducted right before its opening (in July 1993) and before the final closure (in July 1995). The sampling design relies on a stratification of the reef cross-section into reef flat, inner slope and lagoon (Kulbicki et al. 1996). These correspond to distinct habitats that can explain differences in observed fish communities; 69 stations were surveyed in total. Stations were randomly sampled within a given stratum. At each station, an Underwater Visual Census (UVC) was conducted by two scuba divers along a $50 \mathrm{~m}$ linear transect. Each fish observed was identified at the species level and the abundance per species was estimated by the distance sampling method (Buckland et al. 1993; Kulbicki and Sarramegna 1999). Density (in number of individuals $\mathrm{m}^{-2}$ ), biomass (in $\mathrm{g} \mathrm{m}^{-2}$ ) and size distribution were estimated for each species.

\subsection{Methods}

Because station locations could not be matched between 1993 and 1995, spatial variation due e.g. to habitat heterogeneity was accounted for in the analysis by assigning transects to habitats. This was achieved by a cluster analysis of 67 stations relying on environmental data (Pelletier et al. 2004) (Table 3). This description of habitat was considered to be more precise than the initial stratification based on geomorphology.

A large number of species (374) was observed during the survey. This very high diversity, typical of coral reefs, made it difficult to study the impact of marine reserves at the species level. So, species were grouped on the basis of species traits that may be a priori relevant to explain reserve impact. The criteria considered were mobility (Grimaud and Kulbicki 1998), feeding habits defined by Kulbicki et al. (1994), taxonomy, adult size and life history traits (LHT) (Kulbicki et al. 1996) (Tables 1 and 2). For taxonomy only nine families were retained (Table 1) (41 families were recorded during the survey) either because they account for most of the fish abundance or because they are primary targets for fishers, i.e. 246 species
( $82 \%$ of total density). For each criterion, density, species richness, biomass and mean size per transect were estimated per species group.

The impact of the opening to fishing on fish community was first evaluated from fixed-effects linear models. A model was fitted separately for each criterion and each variable i.e. density, biomass, species richness and mean size. Qualitative variables were introduced in the model to explain previous variables, i.e. a habitat factor (5 levels, Habitats 1 and 2 in Table 3 were merged), a year factor (2 levels 1993 and 1995), a reserve area factor ( 2 levels: $\mathrm{A}$ and $\mathrm{B}, \mathrm{A}$ for transects located in the area closed since 1990, and B for transects located in the area open to fishing between 1993 and 1995), and a species group factor. The number of levels of this last factor depended on the criteria specified here above (Tables 1 and 2). In a given model, the impact of the opening to fishing of area B was tested through interaction terms involving the reserve area and year factors. Among these terms, if there was only a significant interaction between reserve and year, the effect of the opening of fishing was the same for all species groups and habitats. In contrast, when there was a significant interaction between reserve, year and species group, the effect of the opening of fishing differed among species groups.

Mean size was modelled through an ANOVA model, while a log-linear model was used for density and biomass. Species richness was modelled from a GLM with a Poisson distribution. Models were selected to retain only significant terms (Venables and Ripley 1997). Multiple comparisons were used to test for differences in variables between areas and years, possibly depending on species group. This enabled us to assess the sign of the differences.

Linear models allowed to assess the effects for each variable separately. In order to compare the effect of the opening to fishing simultaneously on several variables a different type of model was needed. Partial Least Square (PLS) regression (Tenenhaus 1998) makes it possible to test simultaneously the effects of several factors on a set of $Y$ variables. This way, the effects of factors may be evaluated and compared across $Y$ variables. PLS regression relies on the NIPALS algorithm (Wold 1966). This algorithm seeks to maximise the covariance between a linear combination of the dependent $(Y)$ variables, and a linear combination of the explicative $(X)$ variables. This criterion is similar to that of Canonical Correlation Analysis, but PLS regression allows in addition to predict dependent variables from the model and requires no hypothesis on the distribution of the $X$ variables. In addition, missing data are allowed by the NIPALS algorithm. The PLS prediction model is expressed as a linear combination of uncorrelated components that are ordered according to the variance they account for. The PLS regressions were performed with the SIMCA-P software version 10.0 (Umetrics, Inc.).

In this analysis, PLS regressions were used to model density, biomass, size and species richness as a function of the factors already used in linear models. Qualitative variables (habitat, year, reserve area and species group factors) were coded as binary variables, with one variable for each category of possible factor combinations (also called disjunctive coding). A PLS model was fit for each criterion used for grouping species. For each criterion, we compared the variance explained by 
Table 1. Criteria and species groups considered. For each criterion, all species were assigned to a group, except in the case of taxonomy for which only nine families were retained in the study (the most abondant and target fishes).

\begin{tabular}{llll}
\hline Trophic & Mobility & Taxonomic & Adult size \\
& Space occupation & family & $0-7 \mathrm{~cm} \mathrm{(S)}$ \\
\hline Piscivores (Pi) & Territorial (Ter) & Acanthuridae & $8-15 \mathrm{~cm}(\mathrm{M})$ \\
Macrocarnivores (MC) & Sedentary (Sed) & Chaetodontidae & $15-50 \mathrm{~cm}(\mathrm{~L})$ \\
Microcarnivores (mC) & Weak mobility $(\mathrm{Wmb})$ & Labridae & $>50 \mathrm{~cm}(\mathrm{XL})$ \\
Coral feeders (Co) & High mobility (Hmb) & Lethrinidae & \\
Herbivores (He) & & Lutjanidae & \\
Microalgae feeders - & & Pomacentridae & \\
detritivores (mAD) & & Scaridae & \\
Zooplankton feeders (Zoo) & & Serranidae & \\
& & Siganidae & Others \\
\hline
\end{tabular}

Table 2. Life history traits (LHT) used to determine groups for the LHT criterion (from Kulbicki et al. 1996).

\begin{tabular}{|c|c|c|c|c|c|}
\hline $\begin{array}{cc}\text { LHT } \\
\text { Group }\end{array} \quad \begin{array}{c}\text { LHT } \\
\text { category }\end{array}$ & $\begin{array}{l}\text { Age at first } \\
\text { reproduction } \\
\quad \text { (year) }\end{array}$ & $\begin{array}{l}\text { Individual } \\
\text { growth rate }\end{array}$ & Natural Mortality & $\begin{array}{l}\text { Average life } \\
\text { time (year) }\end{array}$ & $\begin{array}{c}\text { Adult } \\
\text { size }(\mathrm{cm})\end{array}$ \\
\hline 1 & 1 & high & high & $0.5-3$ & $<30$ \\
\hline 2 & $1-3$ & $\begin{array}{l}\text { first high, then } \\
\text { medium }\end{array}$ & medium & $3-7$ & $<30$ \\
\hline 3 & $2-3$ & medium & medium & $3-7$ & $<30$ \\
\hline 4 & late & $\begin{array}{l}\text { first high, then } \\
\text { low }\end{array}$ & low & $7-12$ & $<30$ \\
\hline 5 & late & $\begin{array}{l}\text { first high, then } \\
\text { low }\end{array}$ & low & $7-12$ & $30-50$ \\
\hline 6 & very late & low & very low & $>12$ & $50-100$ \\
\hline
\end{tabular}

each variable, and global model fits were compared across criteria. Projections of $Y$ and $X$ variables on the two main components made it possible to evaluate similarities between the variations of $Y$ variables, and to identify the relationships between the $Y$ variables and the $X$ variables, i.e. the categories of combinations of reserve, year and species group factors, e.g. the category area A*year $1993 *$ piscivore. Such projections provide a graphical representation of results that is most helpful to visualize simultaneously many categories and variables.

\section{Results}

ANOVA and GLM fits were generally good for all criteria and all variables (Table 4), the residuals of these models conforming to the Gaussian assumption. The models with the lowest fit were those related to the mean size and biomass of taxonomic groups, and species richness of adult size groups Note that model goodness-of-fit varied from one criterion to the other, but that it was generally similar across criteria for a given variable. The variances explained by PLS models for each variable (Table 5) were found to be consistent with ANOVA and GLM. The best global fits (last column in Table 5) were obtained for the trophic and mobility criteria.
Table 3. Mean of environmental variables per habitat category. Values are expressed in percent cover of the ground for substrate, and for epibenthos variables (Pelletier et al. 2004).

\begin{tabular}{|c|c|c|c|c|c|c|}
\hline & \multicolumn{7}{|c|}{ Habitat } \\
\hline & hab1 & hab2 & hab3 & hab4 & hab5 & hab6 \\
\hline Nb. of stations & 14 & 3 & 20 & 11 & 11 & 8 \\
\hline Depth (m) & 1 & 8 & 2 & 1 & 6 & 8 \\
\hline Sand (\%) & 2 & 2 & 6 & 3 & 48 & 12 \\
\hline Gravel (\%) & 7 & 7 & 18 & 55 & 9 & 10 \\
\hline Boulder (\%) & 7 & 30 & 34 & 22 & 9 & 9 \\
\hline Beach rock (\%) & 84 & 62 & 41 & 18 & 27 & 18 \\
\hline Coral patch (\%) & 0 & 0 & 0 & 1 & 6 & 50 \\
\hline Algae (\%) & 14 & 58 & 11 & 8 & 3 & 9 \\
\hline Living coral (\%) & 4 & 3 & 2 & 1 & 5 & 37 \\
\hline
\end{tabular}

The combination of mean size variable and adult size criterion led to a very good fitting due to the correlation between the variable and the criterion. This was also valid to a lesser extent for the LHT criterion which includes size considerations. 
Table 4. R-squares of ANOVA and model deviances of General Linear Models for each variable (mean size, biomass, density, species richness) and each criterion (trophic, mobility, taxonomy, LHT, adult size).

\begin{tabular}{|c|c|c|c|c|}
\hline Criterion & \multicolumn{3}{|c|}{ ANOVA } & GLM \\
\hline & Mean size & Biomass & Density & $\begin{array}{c}\text { Species } \\
\text { Richness }\end{array}$ \\
\hline Trophic & 61 & 56 & 78 & 83 \\
\hline Mobility & 70 & 62 & 64 & 87 \\
\hline Taxonomy & 38 & 49 & 74 & 86 \\
\hline LHT & 86 & 50 & 65 & 87 \\
\hline Adult size & 88 & 53 & 60 & 45 \\
\hline
\end{tabular}

Table 5. Percent variance explained for each variable by the PLS model for each criterion. The last column corresponds to the global fit, i.e. the percent variance over all variables explained by the model.

\begin{tabular}{|c|c|c|c|c|c|}
\hline & $\begin{array}{c}\text { Mean } \\
\text { size }\end{array}$ & Biomass & Density & $\begin{array}{c}\text { Species } \\
\text { Richness }\end{array}$ & Total \\
\hline Trophic & 65 & 56 & 74 & 83 & 70 \\
\hline Mobility & 72 & 59 & 61 & 84 & 69 \\
\hline Taxonomy & 43 & 53 & 67 & 84 & 62 \\
\hline LHT & 39 & 50 & 67 & 84 & 60 \\
\hline Adult size & 85 & 54 & 54 & 42 & 59 \\
\hline
\end{tabular}

For both linear and PLS models, best fits were obtained for the species richness variable. Mean size and density performed equally well, while biomass led to slightly less good fits. Moreover, models reveal several significant effects of habitat.

Significant effects of fishing were found for many combinations of criteria and variables (Table 6). For the trophic criterion, a significant effect was found for every variable. On the opposite, no significant effect was found for mobility. For other criteria, results depended on the variable. Overall, more significant effects were evidenced with mean size and species richness than with other variables.

Species richness appeared to be impacted by fishing irrespective of criterion categories, i.e. there were only 1 st order effects. For all criteria, species richness was found to decrease in the open area B, while in the closed area A it either increased (adult size criterion), remained unchanged (trophic and taxonomic criteria), or decreased less in A than in B (LHT criterion). For mean size and density, significant effects of fishing were specific to criterion categories (2nd order effects). Fewer significant effects of fishing were found with the biomass variable.

Model results for density per trophic group showed 1st and 2nd order effects, which means that density variation due to reserve status depends on trophic categories (Fig. 1a). Significant effects $(p<0.1)$ were obtained for piscivores, herbivores and macrocarnivores. For piscivores and herbivores, the density decrease between 1993 and 1995 was lower in the protected area A than in the area B open to fishing. In contrast, for macrocarnivores, density decreased in B, but slightly increased in A. Hence, for these three groups, results may be
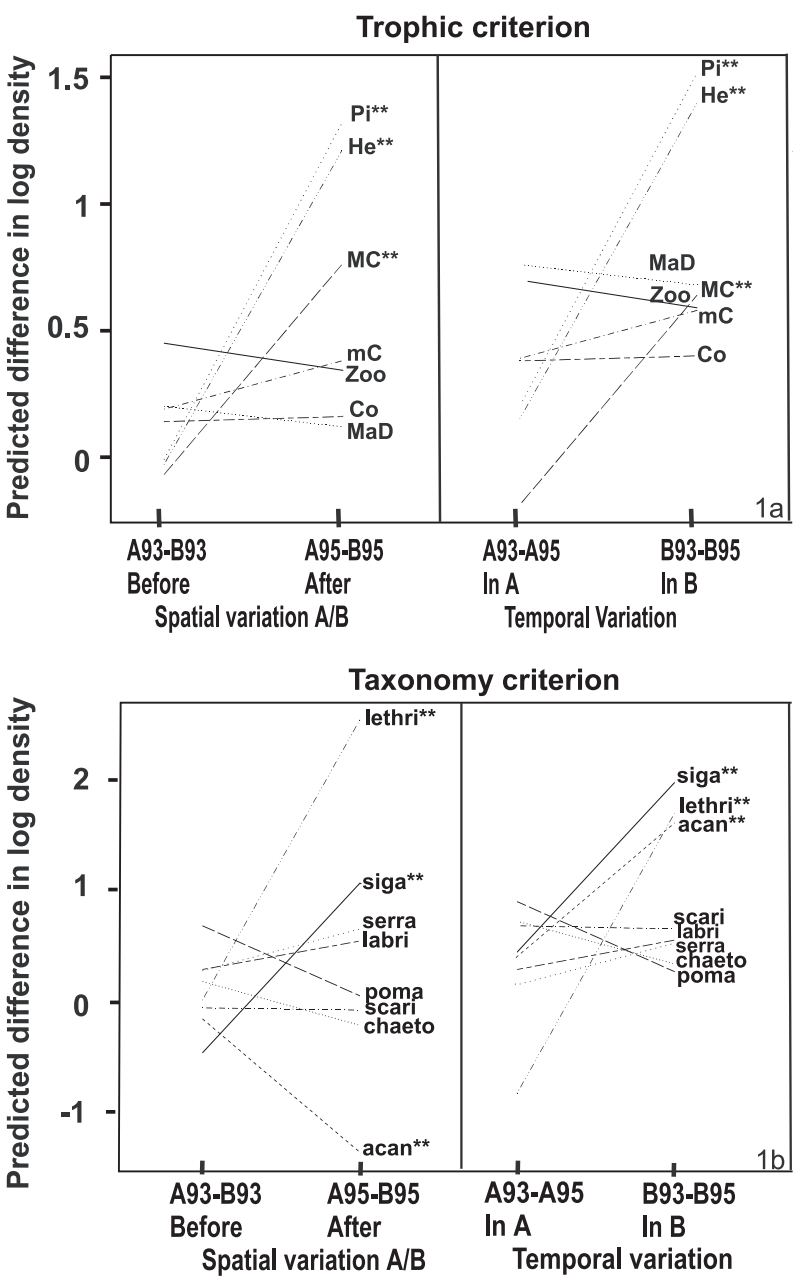

Fig. 1. Differences in density as predicted by the ANOVA models in the case of (a) trophic and (b) taxonomic criteria. Pi: Piscivores, He: Herbivores, mAD: Microalgae feeders detritivores, MC: Macrocarnivores, mC: Microvarnivores, Zoo: Zooplankton feeders, Co: Coral feeders. Siga: Siganidae, Lethri: Lethrinidae, Acan: Acanthuridae, Scari: Scaridae, Labri: Labridae, Serra: Serranidae, Chaeto: Chaetodontidae, Poma: Pomacentridae. ${ }^{* *}$ spatial variation or temporal variation significant at 0.05 level.

seen as a positive impact of protection by reserve status. Model results for density per taxonomic family also showed 1st and 2nd order effects, which means that density variation due to reserve status depended on families (Fig. 1b). Significant effects $(p<0.1)$ were obtained for Lethrinidae, Acanthuridae and Siganidae. For Lethrinidae, density increased in A between 1993 and 1995, while it decreased in B during the same period. For Siganidae, the density decrease between 1993 and 1995 was lower in A than in B. In contrast, Acanthuridae density significantly increased in B but decreased in A. Hence, a positive impact of protection by reserve status was observed for Lethrinidae and Siganidae, but an apparently negative effect was observed for Acanthuridae. Model results for other criteria did not exhibit 2 nd order effects. For the adult size criterion, a significant 1 st order effect was evidenced, i.e. density variation was the same for all categories. This effect corresponded to an increase in $\mathrm{A}$ and a decrease in $\mathrm{B}$, i.e. a positive effect 
Table 6. Impacts of fishing estimated from ANOVA and GLM models. The 1st order effect correspond here to a significant interaction between the factors area and year. The 2nd order effect corresponds here to a significant interaction between the factors area, year and species group. The effect was reported as non-significant when $p$ was larger than 0.1 .

\begin{tabular}{|c|c|c|c|c|}
\hline Criterion & Density & Mean size & Biomass & Species Richness \\
\hline Trophic & $\begin{array}{l}\text { 1st order }(0.00) \\
2 \text { nd order }(0.06)\end{array}$ & 1st order $(0.07)$ & 1st order $(0.02)$ & 1st order $(0.04)$ \\
\hline Mobility & no effect & no effect & no effect & no effect \\
\hline Taxonomy & $\begin{array}{l}\text { 1st order }(0.00) \\
2 \text { nd order }(0.00)\end{array}$ & no effect & no effect & 1st order $(0.00)$ \\
\hline LHT & no effect & $\begin{array}{l}\text { 1st order }(0.00) \\
2 \text { nd order }(0.00)\end{array}$ & 2 nd order $(0.04)$ & 1st order $(0.02)$ \\
\hline Adult size & 1st order $(0.02)$ & $\begin{array}{l}1 \text { st order }(0.03) \\
2 \text { nd order }(0.01)\end{array}$ & no effect & 1 st order $(0.07)$ \\
\hline
\end{tabular}

of reserve status. For mobility and LHT criteria, no significant effect was found; hence there was no significant variation of density due to reserve status.

For the mean size variable, model results with LHT criterion showed 1 st and 2 nd order effects, so mean size variation depended on LHT categories. The 2nd order effect was found significant for all categories (Fig. 2a). The mean size of categories 1, 5 and 6 increased inside $\mathrm{A}$ and decreased in B between 1993 and 1995, which corresponds to a positive effect of reserve status. These categories include small short-lived species (category 1), and medium and large long-lived species (categories 5 and 6). For category 4 (small long-lived species), mean size slightly decreased in A and increased in B, therefore the effect of reserve status may be seen as negative. For categories 2 and 3 (small species with intermediate LHT features), mean size increased slightly more in B than in A, which would mean a negative effect of reserve status. Model results with the adult size criterion also showed 1 st and 2 nd order impacts, so mean size variation depends on adult size categories. The 2 nd order effect was found significant for the large species category (Fig. 2b). Thus, between 1993 and 1995, the mean size of large species increased in A and decreased in B, leading to a positive effect of reserve status. For the trophic criterion, a significant 1 st order effect was evidenced, i.e. mean size variation was the same for all categories. This effect corresponded to an increase in A and a decrease in B, i.e. a positive effect of reserve status. For mobility and taxonomy criteria, no significant effect was found; hence there was no significant variation of mean size due to reserve status.

Regarding biomass, model results with the LHT criterion showed 2nd order effects. A significant 2 nd order effect was found for category 6 (large long-lived species) (Fig. 3). For this category, biomass decreased between 1993 and 1995, but less in A than in B. This effect may be seen as a positive effect of reserve status.

For the trophic criterion, a significant 1 st order effect was evidenced, i.e. biomass variation was the same for all categories. Biomass was found to decrease in both areas, but more in B than in A, which corresponds again to a positive effect of reserve status. For mobility, taxonomy and adult size, no significant effect was found, hence there was no significant variation of biomass due to reserve status.
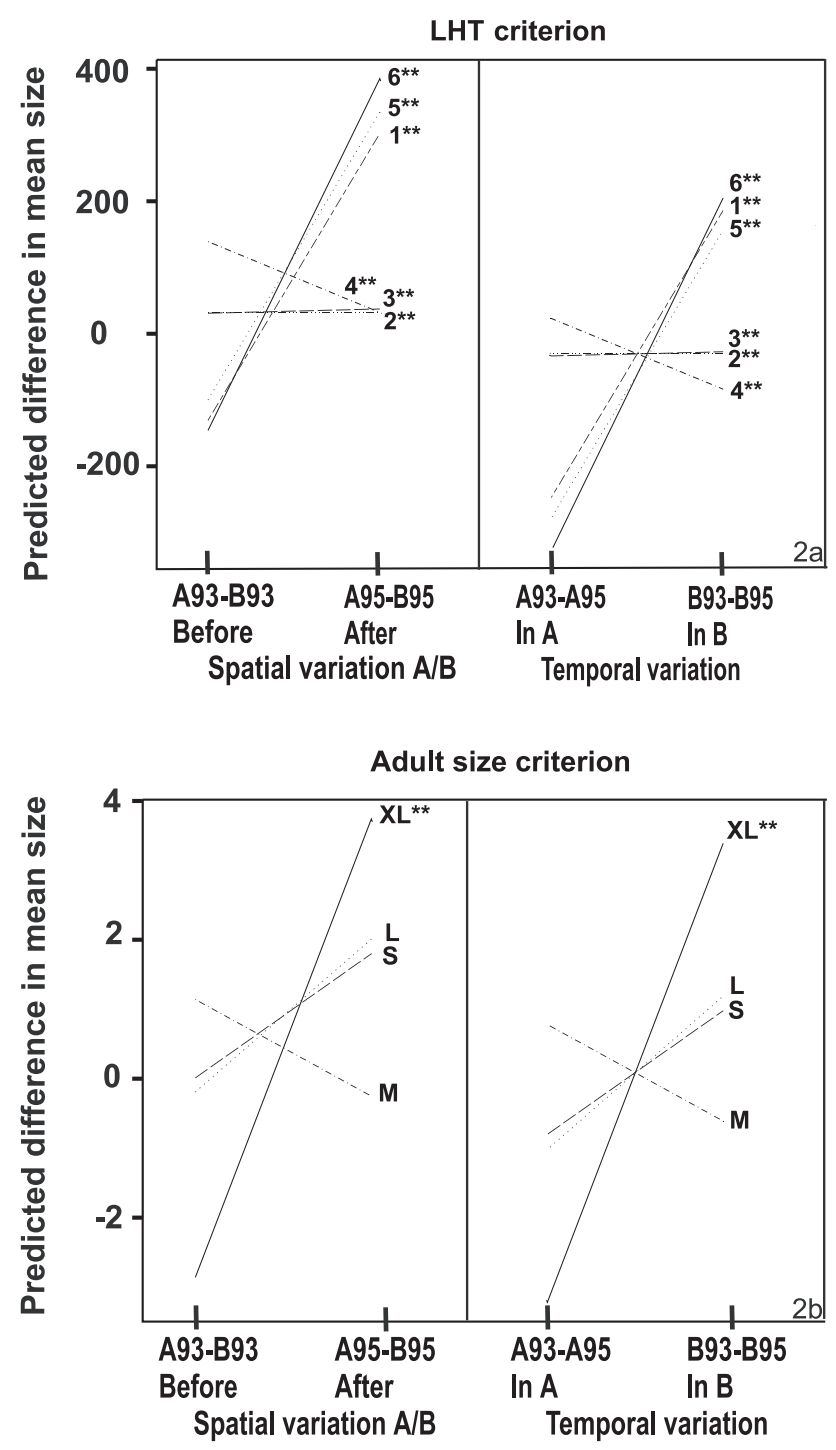

Fig. 2. Differences in mean size as predicted by the ANOVA models in the case of (a) LHT, life history traits, and (b) adult size criteria. LHT 1 - LHT 6: see Table 2. S: 0-7 cm, M: 8-15 cm, L: $15-50 \mathrm{~cm}$, $\mathrm{XL}:>50 \mathrm{~cm} . * *$ spatial variation or temporal variation significant at 0.05 level. 


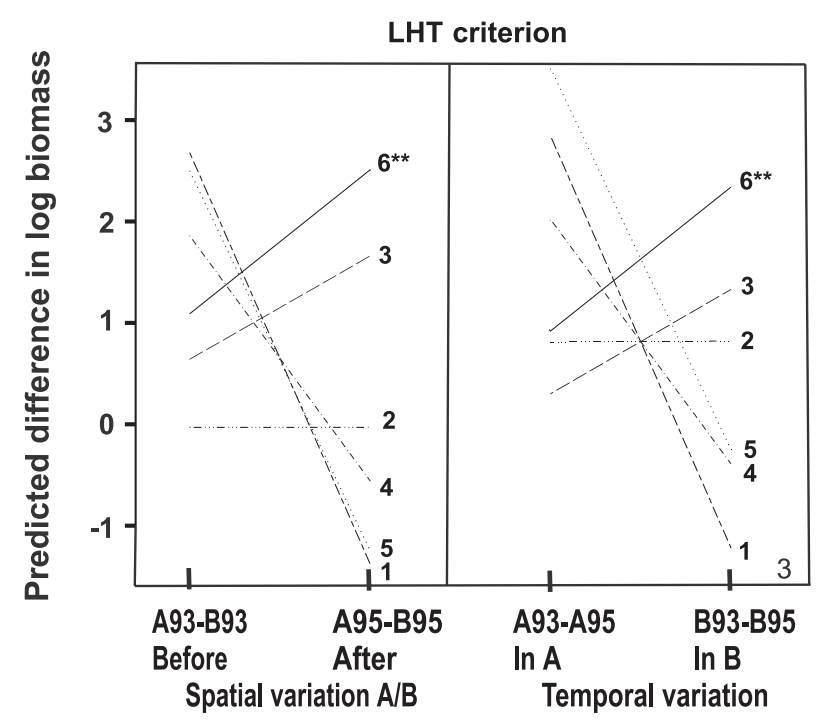

Fig. 3. Differences in biomass as predicted by the ANOVA models in the case of life history traits (LHT) criterion. ${ }^{* *}$ spatial variation or temporal variation significant at 0.05 level.

PLS models including all four variables were then examined. The first two components of the PLS model captured between $55 \%$ and $61 \%$ of the total variance depending on the criterion (Figs. 4 and 5). Projections of variables showed in all cases density and richness being consistently well-represented by the first component, whereas mean size was either opposed to the latter (for adult size and LHT criteria) or well-represented on the second component (for trophic and taxonomy criteria). Biomass was generally not well explained by the PLS models. Global fits were best for the trophic and mobility criteria (Table 5). Projections of variables corresponding to combinations of categories of species group, year and area (Figs. 4 and 5) confirmed ANOVA results (Figs. 1 to 3), in that comparison of 1993-1995 variations between areas A and B for some species groups indicated substantial changes over time. In constrast to ANOVA, results may be interpreted for all variables together. For instance, in the case of piscivores, projection on the first component showed that density decreased more in B that in A (Fig. 4a), while projection on the second component showed that mean size increased substantially in A, while it decreased in B. Species richness of the piscivore group had the same pattern as density, however no corresponding effect was found significant in linear models. Variations for herbivores, macrocarnivores, zooplankton feeders (Fig. 4a), Lethrinidae, Lutjanidae, Serranidae, Pomacentridae, Labridae (Fig. 4b) and LHT categories 1, 2 and 6 (Fig. 5a) may be interpreted in a similar way. Another illustration is provided by the adult size criterion (Fig. 5b). The significant ANOVA effect for large species (XL in Fig. 2b) is also noticeable in Figure $5 b$ by the small variations on the first component which essentially explain mean size. In addition, the first component explained a much larger fraction of the total variance than the second component (see axes of Fig. 5b). Variations on the second component appeared consistent accross adult size categories, with the exception of the slight increase of XL group in area A. However PLS results were only significant for the $\mathrm{S}$ group.
Trophic criterion

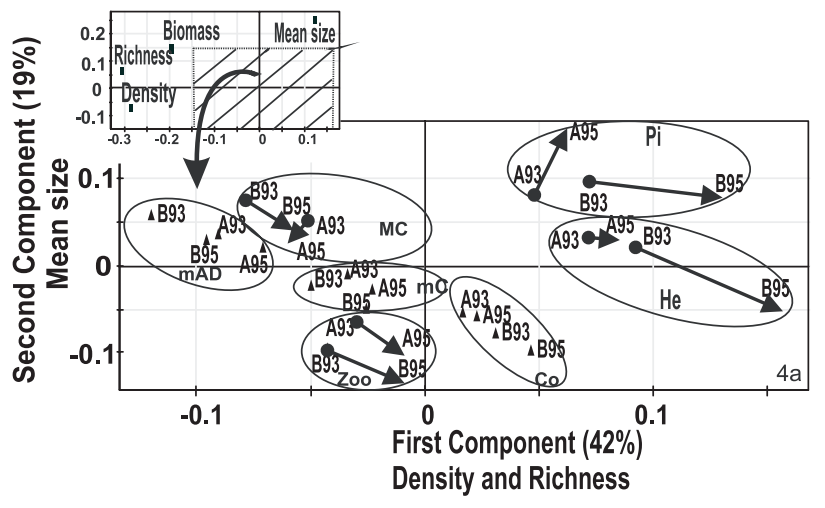

Taxonomy criterion

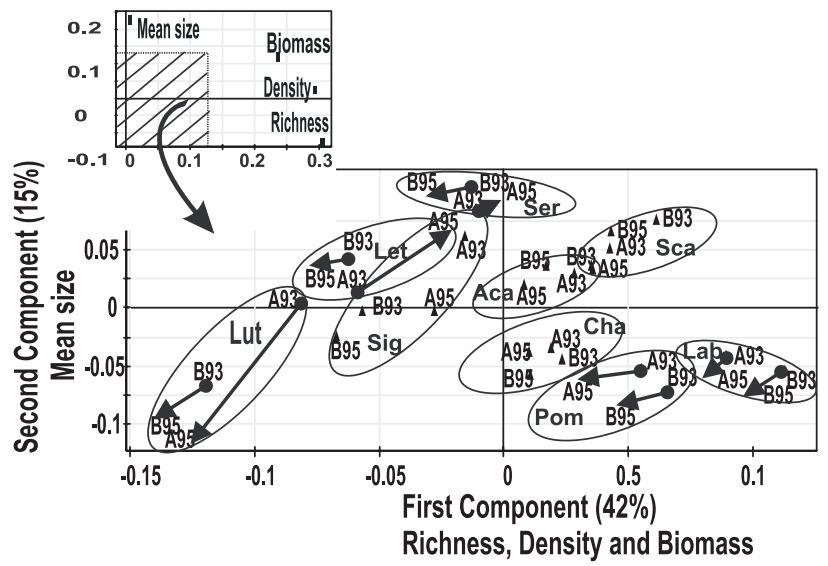

Fig. 4. Projections of variables on the first two components of the Partial Least Square model in the case of the trophic criterion (a), and in the case of the taxonomic criterion (b). Log (density), log (biomass), species richness and mean size were variables, while the other variables corresponded to combinations of categories of species group, year and area and were used to explain the $Y$ variables. These $X$ variables were coded as binary variables in the PLS model. Arrows indicate the temporal variations between the $X$ variables that are significant in the PLS model. The percent variance explained by each component for the whole set of variable was reported between parentheses on the $Y$ - and $X$-axes. The percent variance explained by the first two PLS components for each variable was a) in the case of trophic criterion: biomass $(29 \%, 17 \%)$, density $(60 \%, 3.8 \%)$, richness $(70 \%, 3.8 \%)$, mean size $(12 \%, 50 \%)$; b) in the case of taxonomy criterion: biomass $(41 \%, 11 \%)$, density $(62 \%, 0.7 \%)$, richness $(67 \%$, $10 \%)$, mean size $(0.02 \%, 38 \%)$.

\section{Discussion}

\subsection{Interpretation of results for the Abore reef fish community}

The models show a number of cases where no impact of the opening of fishing could be evidenced. These included the mobility criterion, which surprisingly never showed a significant effect. In the literature, mobility is generally thought as an important criterion for determining species sensitivity to reserve status. For the most mobile species this can be due to the fact than the area open to fishing is adjacent to the protected 

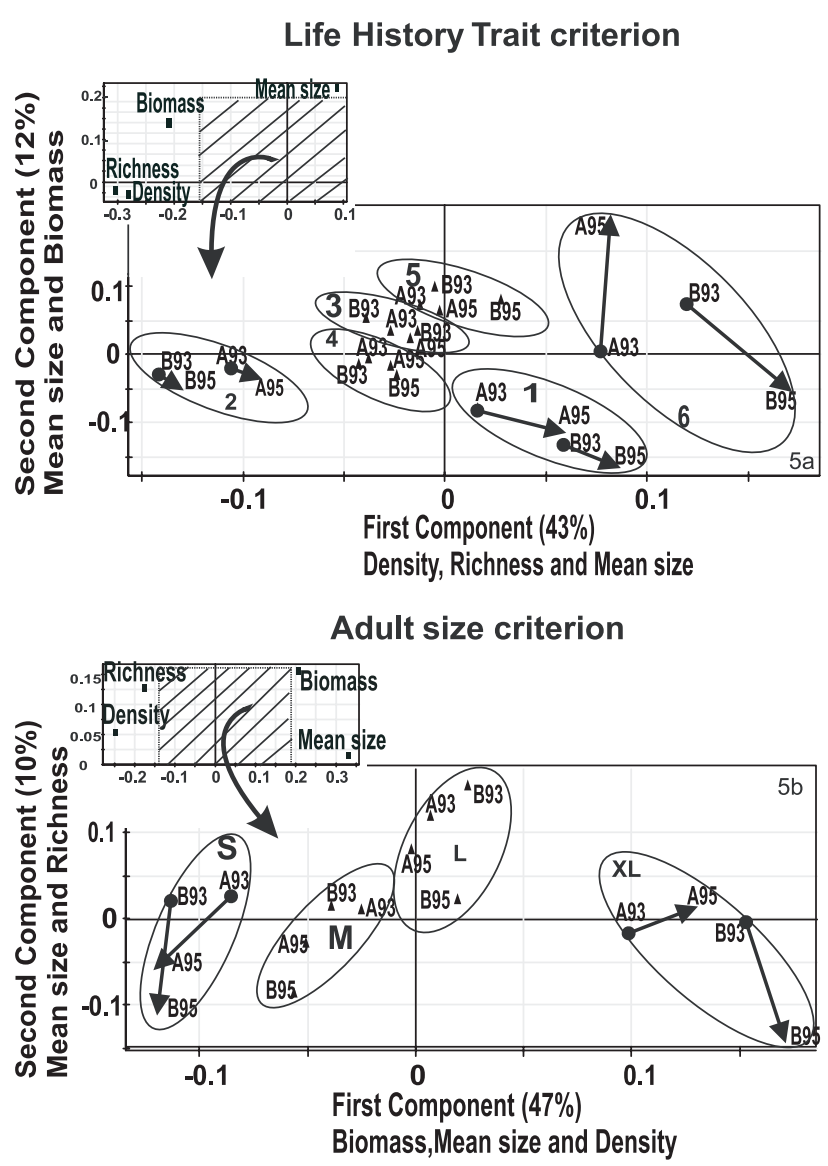

Fig. 5. Projections of variables on the first two components of the PLS model in the case of the LHT criterion (a), and in the case of the adult size criterion (b). Log (density), $\log$ (biomass), species richness and mean size were $(Y)$ variables, while the other variables corresponded to combinations of categories of species group, year and area and were used to explain the $Y$ variables. These $X$ variables were coded as binary variables in the PLS model. Arrows indicate the temporal variations between the $X$ variables that are significant in the PLS model. The percent variance explained by each component for the whole set of variables was reported between parentheses on the $Y$ and $X$-axes. The percent variance explained by $Y$ variables was a) in the case of LHT criterion: biomass $(33 \%, 15 \%)$, density $(61 \%, 8 \%)$, richness $(71 \%, 0.1 \%)$, mean size $(57 \%, 33 \%)$; b) in the case of taxonomy criterion: biomass $(84 \%, 0.3 \%)$, density $(49 \%, 3 \%)$, richness $(23 \%, 14 \%)$, mean size $(57 \%, 33 \%)$.

area. On the opposite, territorial and sedentary species are the least targeted by fishing and therefore no reserve status effect were expected nor found. The biomass variable also appeared to be less affected by reserve status than the other variables, probably because of the larger variance of this variable.

In contrast to mobility, significant effects due to reserve status could be evidenced for other criteria (Table 7). In a number of cases, only 1 st order effects were significant, i.e. the opening of fishing affected all species groups in a similar way for the criterion considered. For instance, a positive effect on species richness was observed whatever the criterion, with the exception of mobility. Positive effects were also observed for this variable in other studies (e.g. Letourneur 1996; Wantiez et al. 1997; Johnson et al. 1999). However in the literature species richness was often found to be less sensitive to reserve status than density, size or biomass. In this study, species richness was sensitive to the impact of the opening of fishing, but only at the community level. We hypothesize this might be related to the relative robustness of this variable which is based on presence/absence of species compared with mean size or density which are liable to be influenced by a few large values. An impact of reserve status may then appear on the whole fish community, but not at species groups levels. As for other variables, significant 1 st order effects were observed in a few cases (Table 7), say global mean size and global biomass for the trophic criterion, and global density for the adult size criterion. These effects were all positive.

In other cases, significant 2 nd order effects were evidenced (Table 7). Most effects were positive effects of reserve status. Corresponding species groups included Lethrinidae, top predators (macrocarnivores and piscivores), which were also large long-lived species (XL group and LHT groups 5 and $6)$. The density, mean size and biomass of these species were all positively impacted by reserve status, or equivalently negatively impacted by the opening of area B to fishing. Note that all observed Lethrinidae were macrocarnivores. Herbivores and Siganidae were also positively affected (note that Siganidae are either herbivore or microherbivore species). Consistently with existing literature (see e.g. Russ and Alcala 1996; Chiappone et al. 2000), we assume that positive effects on all these species groups were due to the fact they were target species for fishers. In a few cases, 2nd order effects were negative effects of reserve status. These corresponded to Acanthuridae density and to the mean size of short and medium long-lived species (LHT groups 2 and 4). In the first case, density decreased in $\mathrm{A}$ and increased in $\mathrm{B}$, while in the second case, mean size increased in both areas, but less in A than in B. Such negative effects on family density have already been observed in several cases, e.g. for Mullidae and Labridae (Letourneur 1996), and Acanthuridae (Wantiez et al. 1997).

In some cases, a priori expected 2nd order effects were not observed, e.g. for mean size per trophic group and per family, and also for density per LHT. A decrease in the mean size of top predators and a larger impact on large long-lived species would seem intuitive. There are several possible explanations to these results. First, the behaviour of some species groups, in particular those targeted by fishing, may be affected by the presence of observers or fishers. Second, several fish species, and particularly top predators, are not fished in New Caledonia, due to problems of ciguatera poisoning. The third possible explanation is that most large species display naturally low densities and that the sampling effort was to sufficient to detect changes. An additional explanation for mean size is that a 3 year period of time is not sufficient to allow species with slow growth to increase substantially in length.

\subsection{Potential indicators for reserve impact assessment}

Previous results provide elements for proposing variables and criteria that are suitable to assess the impact of reserve status upon fish community. First, species richness is a good candidate, because it is very well modelled by GLM and PLS 
Table 7. Summary of significant effects of reserve status for all variables and all criteria. " $A$ " is the closed area and " $B$ " the area opened between 1993 and 1995. Global means that the effect was the same for all species group (1st order effect).

\begin{tabular}{|c|c|c|c|c|c|}
\hline & Variation & Trophic & Taxonomic & Adult size & LHT \\
\hline \multirow{4}{*}{$\begin{array}{l}\text { Positive } \\
\text { effects of } \\
\text { reserve } \\
\text { status }\end{array}$} & $\uparrow A$ and $\downarrow \mathrm{B}$ & $\begin{array}{l}\text { macrocarnivore } \\
\text { density } \\
\text { global mean size }\end{array}$ & $\begin{array}{l}\text { Lethrinidae } \\
\text { density }\end{array}$ & $\begin{array}{l}\text { XL mean size } \\
\text { global species } \\
\text { richness } \\
\text { global density }\end{array}$ & $\begin{array}{l}\text { mean size of } \\
\text { groups } 1,5 \text { and } 6\end{array}$ \\
\hline & $\uparrow \uparrow A$ and $\uparrow B$ & & & & $\begin{array}{l}\text { mean size } \\
\text { of group } 3\end{array}$ \\
\hline & $\rightarrow \mathrm{A}$ and $\downarrow \mathrm{B}$ & $\begin{array}{l}\text { global species } \\
\text { richness }\end{array}$ & $\begin{array}{l}\text { global species } \\
\text { richness }\end{array}$ & & \\
\hline & $\begin{array}{l}\downarrow \mathrm{A} \text { and } \\
\downarrow \downarrow \mathrm{B}\end{array}$ & $\begin{array}{l}\text { piscivore density } \\
\text { herbivore density } \\
\text { global biomass }\end{array}$ & $\begin{array}{l}\text { Siganidae } \\
\text { density }\end{array}$ & & $\begin{array}{l}\text { biomass of } \\
\text { group } 6 \\
\text { global species } \\
\text { richness }\end{array}$ \\
\hline \multirow{2}{*}{$\begin{array}{l}\text { Negative } \\
\text { effects of } \\
\text { reserve } \\
\text { status }\end{array}$} & $\downarrow \mathrm{A}$ and $\uparrow \mathrm{B}$ & & $\begin{array}{l}\text { Acanthuridae } \\
\text { density }\end{array}$ & & $\begin{array}{l}\text { mean size of } \\
\text { group } 4\end{array}$ \\
\hline & $\uparrow A$ and $\uparrow \uparrow B$ & & & & $\begin{array}{l}\text { mean size of } \\
\text { group } 2\end{array}$ \\
\hline
\end{tabular}

regressions, and richness at the level of the whole fish community is sensitive to the impact of the opening of fishing. Other possible indicators pertain to particular species groups. Relationships between species groups relative to distinct criteria lead us to propose on the one hand, Lethrinidae density, Siganidae density, and piscivore density, and on the other hand, the mean size of large species and the mean size of long-lived species. These potential indicators were negatively affected by the opening of fishing, and should be positively affected by reserve status. Note that Lethrinidae density and the mean size of large long-lived species were always positively impacted in area A. In contrast, Acanthuridae density could also be considered as in indicator that is negatively affected by reserve status.

Results of ANOVA and GLM indicate that the opening of fishing significantly impacts several variables that pertain to different ecological effects. Overall, these effects are consistent with expected increases in species richness, density, mean size and biomass, within the protected area. PLS results confirm that several measures of fish community attributes are independently affected because the impact of the opening of fishing is well represented on bipolar components of the model. For instance, we often observed an impact on density and richness for one component, and an impact on mean size on the other component. It is thus necessary to consider complementary indicators to take account of the diversity of impacts at the community level. Beyond the choice of variables sensitive to reserve status, our results showed that species groups are diversely affected depending on criteria considered for partitioning the community. Furthermore, sensitivity to the opening of fishing depended on both criterion and variable. Several combinations of criterion and variable corresponded to intuitively expected effects, whereas others were either not observed before or do not correspond to intuition.

When defining ecological indicators, it is also necessary to take into consideration the accuracy and precision of candidate variables. Global species richness may be seen as a robust measure of the global abundance of the whole fish community because it relies on presence/absence data. In contrast, density and mean size variables are less robust in that they are quantitative measurements which are more sensitive to a few outlying observations. Furthermore, density and mean size are subject to potential systematic error like multiple counting of the same fish. Additional measurement error occurs in the case of mean size due to a lack of precision on size estimation. All variables are affected by observability issues related to species behaviour, e.g. attraction or fear of observer, and cryptic or nycthemeral behaviour (Kulbicki 1998b). Estimation errors in variables were not explicitly modelled here.

The method used relies on inferential models including factors that are deemed to be explicative of the spatial variations of abundance, size and diversity of fish community. Habitat appears as a determining factor in this respect, since models revealed several significant habitat effects. Accounting for habitat is necessary to avoid confusion with effects of reserve status. Using PLS regressions allows to confront within a single model a criterion to a range of different variables, and to stress their relationships with factors linked to reserve status. It should be noted that our analysis was aimed at evaluating the impact of an opening to fishing rather than a reserve effect. The opening to fishing is expected to result in a quick change in biological variables in the exploited area, due to the removal of large individuals (decreases in mean size and in density, and consequently in biomass). In contrast, the reserve effect corresponds to a rebuilding of fish community which is expected to result in a slower increase of those variables in the protected area. Assessment of the impact of fishing is probably more direct on the short term, particularly because the opening induced a sharp increase in fishing intensity. In addition, in the case of Abore, the age of the reserve (3 years) may not have been sufficient to already observe restoration effects 
on the whole fish community. Our approach may be applied to other cases of reserve with other kinds of fish community, provided that the experimental design is appropriate for constructing an inferential model and testing effects of reserve status. More generally, it can be applied to any kind of ecological impact that is spatially constrained.

The present analysis is a first step towards the definition of ecological indicators for assessing the impact of reserve status on the Abore reef fish community. It enabled us to evaluate the sensitivity of ecological variables to the opening to fishing, but it does not provide comparison accross criteria. Possible ways to go further could consist in combining criteria based on appropriate weighting.

Ecological indicators are helpful to analyse changes in fish community, but they should be an operational tool to assist management decisions. Progresses in the definition of ecological indicators for the Abore reef reserve, and more generally for all the reserves of the Noumea lagoon need further data analysis and modelling, but they mostly require collaborative work with the managers.

Acknowledgements. This work was made possible thanks to a grant of the ZONECO program of New Caledonia. Data were collected by scientists from several institutes during a research project led by Université de Nouvelle-Calédonie (LERVEM) and funded by the South Province (DRN). Additional support was provided by PNEC/ART4.

\section{References}

Agardy M.T., 1994, Advances in marine conservation: The role of marine protected areas. Trends Ecol. Evol. 9, 267-270.

Agardy M.T., 2000, Effects of fisheries on marine ecosystems: A conservationist's perspective. ICES J. Mar. Sci. 57, 761-765.

Alcala A.C., 1988, Effects of marine reserves on coral fish abundances and yields of Philippine coral reefs. Ambio 17, 194-199.

Bohnsack J.A., 1990, Black and Nassau grouper fishery trends. NMFS-SEFSC, Miami.

Bohnsack J.A., Harper D.E., McClellan D.B., 1994, Fisheries trends from Monroe Country, Florida. Bull. Mar. Sci. 54, 982-1018.

Boncoeur J., 2002, Pêche et aquaculture en Nouvelle-Calédonie. In: Perret. C. (Ed.), Perspectives de développement pour la Nouvelle Calédonie. Presses Universitaires de Grenoble, Grenoble, pp. 45-84.

Buckland S.T., Anderson D.R., Burnham K.P., Laake J.L., 1993, Distance sampling. Estimating abundance of biological populations. Chapman and Hall, New York

Chiappone M., Sluka R., Sealey S., 2000, Groupers (Pisces: Serranidae) in fished and protected areas of the Florida Keys, Bahamas and Northern Caribbean. Mar. Ecol. Prog. Ser. 198, 261-272.

Dandonneau Y., Debenay J.P., Dugas F., Fourmanoir P., Magnier Y., Rougerie F., 1981, Le lagon de la Grande Terre. Présentation d'ensemble. Sédimentologie et hydrologie du sud-ouest. Atlas de la Nouvelle-Calédonie et dépendances. IRD, Paris.

FAO 1999, Indicators for sustainable development of marine capture fisheries. Fishery Resources Division, Rome, FAO Technical Guidelines for Responsible Fisheries $N^{\circ} 8$.

Francour P., 1994, Pluriannual analysis of the reserve effect on ichthyofauna in the Scandola natural reserve (Corsica, Northwestern Mediterranean). Oceanol. Acta 17, 309-317.
Garcia S.M., Staples D.J., Chesson J., 2000, The FAO guidelines for the development and use of indicators for sustainable development of marine capture fisheries and an Australian example of their application. Ocean Coast. Manage. 43, 537-556.

Grigg R.W., 1994, Effects of sewage discharge, fishing pressure and habitat complexity on coral reef ecosystems and reef fishes in Hawaii. Mar. Ecol. Prog. Ser. 103, 25-34.

Grimaud J., Kulbicki M., 1998, Influence de la distance à l'océan sur les peuplements ichtyologiques des récifs frangeants de Nouvelle-Calédonie. C.R. Acad. Sci., Ser. III 321, 923-931.

Jennings S., Marshall S.S., Polunin N.V.C., 1996, Seychelles' protected areas: Comparative structure and status of reef fish communities. Biol. Cons. 75, 201-209.

Johnson D.R., Bohnsack J.A., Funicelli N.A., 1999, The effectiveness of an existing no-take fish sanctuary within the Kennedy Space Center, Florida. N. Am. J. Fish. Manage. 19, 436-453.

Karr J.R., 1981, Assessment of biotic integrity using fish communities. Fisheries 6, 21-27.

Kulbicki M., 1997, Bilan de 10 ans de recherche (1985-1995) par l'ORSTOM sur la diversité, la densité, la biomasse et la structure trophique des communautés des poissons lagonaires et récifaux en Nouvelle-Calédonie. Cybium 21 suppl., 47-79.

Kulbicki M., Bargibant G., Menou J.L., Mou Tham G., Thollot P., Wantiez L., Williams J.T., 1994, Évaluations des ressources en poissons du lagon d'Ouvéa. 3ème partie : Les poissons. Convention Sciences de la Mer ORSTOM Nouméa $N^{\circ} 11$.

Kulbicki M., Galzin R., Letourneur Y., Mou-Tham G., Sarramegna S., Thollot P., Wantiez L., Chauvet C., 1996, Les peuplements de poissons de la réserve marine du récif Aboré (NouvelleCalédonie) : composition spécifique, structures trophique et démographique avant l'ouverture à la pêche. Doc. Scient. Techn. IRD, Nouméa.

Kulbicki M., Sarramegna S., 1999, Comparison of density estimates derived from strip transect and distance sampling for underwater visual censuses: A case study of Chaetodontidae and Pomacanthidae. Aquat. Living Resour. 12, 315-325.

Labrosse P., Fichez R., Farman R., Adams T., 2000, New Caledonia. In: Sheppard C. (Ed.) Seas at the Millennium: an environmental evaluation. Elsevier, Amsterdam, pp. 723-736.

Leblic I., 1999, Pêcheurs Kanaks et politiques de développement de la pêche en Nouvelle-Calédonie. In : Blanchet G. (Ed.) Les petites activités de pêche dans le Pacifique sud. IRD, Nouméa, pp. 119-141.

Letourneur Y., 1996, Réponses des peuplements et populations de poissons aux réserves marines : le cas de l'île de Mayotte, océan Indien occidental. Ecoscience 3, 442-450.

Pelletier D., Ferraris J., Amand M., 2004, Evaluating the impact of marine reserves on fish communities: A holistic approach based on statistical models. 4th World Fisheries Congress, May 2-6, 2004, Vancouver, Canada.

Polunin N.V.C., Roberts C.M., 1993, Greater biomass and value of target coral-reef fishes in two small Caribbean marine reserves. Mar. Ecol. Prog. Ser. 100, 167-176.

Roberts C.M., Polunin N.V.C., 1991, Are marine reserves effective in management of reef fisheries? Rev. Fish Biol. Fish. 1, 65-91.

Russ G.R., Alcala A.C., 1996, Marine reserves: Rates and patterns of recovery and decline of large predatory fish. Ecol. Appl. 6, 947-961.

Russ G.R., Alcala A.C., 1998, Natural fishing experiments in marine reserves 1983-1993: Roles of history and fishing intensity in family responses. Coral Reefs 17, 399-416.

Sale P.F., 1998, Appropriate spatial scales for studies of reef fish ecology. Aus. J. Ecol. 23, 202-208. 
Sarramegna S., 2000, Contribution à l'étude des réserves marines du lagon sud-ouest de Nouvelle-Calédonie. Thèse de doctorat. Université Nouvelle-Calédonie, Nouvelle-Calédonie.

Sumaila U.R., Guénette S., Alder J., Chuenpadgee R., 2000, Addressing ecosystem effects of fishing using marine protected areas. ICES J. Mar. Sci. 57, 752-760.

Tenenhaus M., 1998, La régression PLS, théorie et pratique. Editions Technip, Paris.

Venables W.N., Ripley B.D., 1997, Modern applied statistics with Splus. 2nd edn. Springer-Verlag, New York.

Virly S., 2001, Perceptions de l'état de la ressource, du milieu et des mesures de gestion par les pêcheurs professionnels de
Nouvelle-Calédonie : Domaines côtier et lagonaire. IRD Nouméa, Rapp. techn.

Wantiez L., Thollot P., Kulbicki M., 1997, Effects of marine reserves on coral reef fish communities from five islands in New Caledonia. Coral Reefs 16, 215-224.

Wold H., 1966, Estimation of principal components and related models by iterative least squares. In: Krishnaiah P.R. (Ed.), Multivariate Analysis. Academic Press, New York, pp. 391-420.

Zeller D.C., Stoute S.L., Russ G.R., 2003, Movements of reef fishes accross marine reserve boundaries: Effects of manipulating a density gradient. Mar. Ecol. Progr. Ser. 254, 269-280. 